\title{
tic\&société
}

Vol. 13, No 1-2 | 1er semestre 2019 - 2ème semestre 2019

Les industries culturelles à la conquête des

plateformes?

\section{Culturebox, le portail culturel au cœur de la stratégie numérique de France Télévisions}

\section{Lucie ALEXIS}

\section{(2) OpenEdition \\ Journals}

Édition électronique

URL : http://journals.openedition.org/ticetsociete/3226

DOI : 10.4000/ticetsociete.3226

\section{Éditeur}

Association ARTIC

\section{Édition imprimée}

Pagination : 159-193

\section{Référence électronique}

Lucie ALEXIS, "Culturebox, le portail culturel au cœur de la stratégie numérique de France Télévisions », tic\&société [En ligne], Vol. 13, № 1-2 | 1er semestre 2019 - 2ème semestre 2019, mis en ligne le 20 avril 2019, consulté le 14 mai 2019. URL : http://journals.openedition.org/ticetsociete/3226 ; DOI : 10.4000/ticetsociete.3226 
tic\&société - 13(1-2), 2019

\title{
Culturebox, le portail culturel au cœur de la stratégie numérique de France Télévisions
}

\begin{abstract}
Lucie ALEXIS
Lucie Alexis est maîtresse de conférences en sciences de l'information et de la communication à l'Institut Français de Presse de l'université Paris II, au sein du laboratoire CARISM. Elle a soutenu en novembre 2017 une thèse intitulée Réponses à la mission culturelle de la télévision publique. Analyse sémiologique des rapports institutionnels, des figures de l'artiste et des écritures numériques à France Télévisions (1993-2017). lucie.alexis@u-paris2.fr
\end{abstract}


Culturebox, le portail culturel au cœur de la

stratégie numérique de France Télévisions

\section{Culturebox, le portail culturel au cœur de la stratégie numérique de France Télévisions}

Résumé : Cet article porte sur les stratégies éditoriales de France Télévisions dans un contexte concurrentiel marqué par le succès de plateformes telles que YouTube ou Dailymotion dans l'offre de contenus numériques. Plus précisément, il consiste en une étude de Culturebox, le portail numérique de France Télévisions consacré à la culture et refondu en 2013. Nous avons ainsi procédé à une analyse sémiologique des écrans d'accueil du site entre 2014 et 2017, puis rapporté celleci aux choix éditoriaux du groupe de service public. Empruntant au format du magazine culturel en ligne, le dispositif témoigne de logiques d'hybridation à l'œuvre dans la configuration des pratiques d'écritures et des modalités d'exposition des contenus. En outre, il manifeste une politique éditoriale visant à promouvoir une « culture de service public », reproduisant ainsi sur Internet le positionnement culturel identifiable sur l'antenne linéaire de France 2.

Mots-clés: portail, France Télévisions, contenus culturels, mission culturelle publique, formats éditoriaux.

Abstract: This article focuses on the editorial strategies of France Télévisions developed in reaction to the emergence of platforms such as YouTube or Dailymotion which offer digital content. Specifically, it examines Culturebox, the digital portal of France Televisions dedicated to culture and redesigned in 2013. We conducted a semiological analysis of the home pages of the site between 2014 and 2017 and of the public service group's editorial choices. Borrowing from the format of the online cultural magazine, Culturebox illustrates hybridization logics in the configuration of writing practices and content presentation. In addition, its editorial policy aims at promoting a "public service culture", thus reproducing France 2's characteristic cultural positioning on the Internet.

Keywords: portal, France Télévisions, cultural contents, public cultural mission, editoring formats. 


\section{Lucie ALEXIS}

Resumen: Este artículo analiza las estrategias editoriales de France Télévisions en un contexto de competencia marcado por el éxito de plataformas - como YouTube o Dailymotion - en la oferta de contenido digital. Se centra en el estudio de Culturebox, (el portal digital de France Télévisions dedicado a la cultura), que ha sido remodelado en 2013. Se ha realizado un análisis semiológico de las páginas de inicio del sitio citado, entre 2014 y 2017; y posteriormente dicho análisis se relaciona con las decisiones editoriales del grupo de servicio público. Inspirado en el formato de una revista cultural en línea, el dispositivo revela la existencia de lógicas de hibridación presentes en la configuración de las prácticas de escritura y en las modalidades de exposición del contenido. Además, muestra una política editorial dirigida a promover una "cultura de servicio público", reproduciendo así en Internet el posicionamiento cultural que se muestra en la antena de France 2.

Palabras clave: portal, France Télévisions, contenidos culturales, misión cultural pública, formatos editoriales. 
Culturebox, le portail culturel au cœur de la stratégie numérique de France Télévisions

Alors que la transition vers le numérique a « radicalement modifié les conditions d'accès à une grande partie des contenus culturels », comme le montre Olivier Donnat (2010) dans son étude sur Les pratiques culturelles à l'ère numérique, France Télévisions (FTV) a développé son offre de contenus culturels en proposant notamment, en 2013, une nouvelle version du portail Culturebox ${ }^{1}$. Ce dispositif s'inscrit comme le " quatrième pilier ${ }^{2}$ " numérique après francetv info, francetv sport et francetv éducation développés par France Télévisions Éditions Numériques (FTVEN) à cette époque. Nommés des "verticales" au sein de la direction du numérique, ces contenus délinéarisés - appelés ainsi pour les distinguer du " modèle du flot » reposant sur la programmation continue ont pour objet de compléter les services d'édition des chaînes linéaires dans le cadre d'une offre multimédiatique. Culturebox est un portail numérique consacré à la culture. II permet à FTV de montrer son engagement en faveur de la diffusion de la culture ${ }^{3}$.

Dans cet article, nous souhaitons interroger la métamorphose du média télévision et les stratégies éditoriales du groupe audiovisuel public, dans un contexte concurrentiel marqué par le succès de plateformes telles que YouTube ou Dailymotion, dans l'offre de contenus numériques. Nous cherchons à identifier les réponses apportées à celles-ci par FTV dès 2013. Si la filière télévisuelle est particulièrement présente sur YouTube - ainsi que l'ont montré Xavier Levoin et Bastien Louessard (2018) - et que Culturebox possède une chaîne sur les deux plateformes précitées, on peut se demander pourquoi, concernant la programmation culturelle,

${ }^{1}$ Culturebox.francetv.info

2 Entretien inédit de 1 h 21 réalisé le 27 juin 2014 dans les locaux du groupe à Issyles-Moulineaux avec l'un des directeurs de la stratégie à la direction du numérique à FTV, que nous anonymisons ici. Dans la suite de l'article, nous référençons l'entretien comme suit: (Directeur de la stratégie, 27 juin 2014).

${ }^{3}$ Les spectacles diffusés sur Culturebox ne sont cependant pas comptabilisés dans le quota obligatoire d'au moins une émission culturelle par jour en première partie de soirée sur une chaîne du groupe, établi dans le cahier des charges de FTV (voir https://www.legifrance.gouv.fr/affichTexte.do?cidTexte=JORFTEXT000020788471\&c ategorieLien=id). 
FTV a opté pour la création d'une chaîne culturelle numérique. Nous faisons l'hypothèse que la stratégie de Culturebox, en tant que "marque éditeur", a été de se positionner en opposition aux stratégies d'agrégation de contenus telles qu'on les observe à l'époque sur des plateformes comme YouTube ou Dailymotion. Nous avancerons que cette stratégie est liée aux réponses mises en place par le groupe vis-à-vis de sa mission culturelle de service public et que l'on retrouve le même type d'offre culturelle sur le linéaire (en l'occurrence, la chaîne France 2). Notre étude abordera les modalités d'éditorialisation de contenus culturels choisies par un acteur médiatique public pour répondre à l'émergence et à la concurrence de portails de SVOD tels que Netflix et des plateformes d'hébergement, de partage et de visionnage de vidéos en ligne telles que YouTube et Dailymotion.

Pour ce faire, nous nous sommes concentrée sur les formats numériques d'écriture et de diffusion des contenus culturels. Nous procéderons à une analyse sémiologique des écrans d'accueil de Culturebox entre 2014 et 2017, puis rapporterons celle-ci aux choix éditoriaux du groupe de service public. Notre étude empruntera à l'approche par les modèles socioéconomiques des industries culturelles (Miège, 1996; Mœglin, 2005). Cette analyse s'appuiera également sur un entretien mené le 27 juin 2014 avec l'un des directeurs, à l'époque, de la stratégie au sein de la direction du numérique à FTV. Nous complèterons ainsi l'étude des discours des acteurs du groupe avec celle des modalités éditoriales de l'offre proposée.

Tout d'abord, nous présenterons la refonte de Culturebox par l'équipe numérique de FTV. En regard des stratégies éditoriales des plateformes, nous verrons que le groupe a fait le choix d'opter pour un modèle de portail. Nous verrons ensuite que celui-ci intègre des logiques d'hybridation au sein de la configuration des formats éditoriaux des contenus. Le portail est dès lors pensé comme un magazine culturel en ligne revendiquant une fonction médiatrice entre les lecteurs et les contenus. Enfin, le modèle du portail permet à FTV de véhiculer une politique éditoriale en cohérence avec la programmation de 
Culturebox, le portail culturel au cœur de la stratégie numérique de France Télévisions

France $2^{4}$.

\section{La refonte de Culturebox : un portail pour éditorialiser une offre culturelle plurielle}

Alors qu'à la fin de la saison 2013, FTV annonçait la suppression de plusieurs émissions culturelles (entre autres Des mots de minuit ${ }^{5}$, Taratata $^{6}$ et Chabada $^{7}$ ), le groupe a étendu, en juin 2013, l'offre de Culturebox afin de " développer de nouveaux accès à la culture ", selon les propos de Rémy Pfimlin, président de FTV entre 2010 et 2015, rapportés par Le Monde.fr en juin $2013^{8}$. II s'agit de la refonte d'un dispositif portant le même nom, créé en 2007 par France 3. Alimenté par une rédaction numérique qui reprenait les reportages de France 3 Régions, particulièrement ceux de courte durée, ce service de télévision de "rattrapage » devait jouer un rôle de guide culturel. Le site se présentait sous la forme d'une mosaïque, comme le montre la Figure 1, où les vidéos étaient animées de façon aléatoire. II était possible de filtrer les émissions par région.

\footnotetext{
${ }^{4}$ Indiquons ici que, depuis la fusion en 2016 du site de Radio France avec le site Francetv info, Culturebox est intégré au dispositif Franceinfo.

5 Des mots de minuit est un magazine culturel diffusé entre 1999 et 2013 sur France 2 et présenté par Philippe Lefait. L'émission est réactivée en version web sur Culturebox à partir de juillet 2014.

6 Taratata est une émission musicale diffusée entre 1993 et 2013 sur France 2 et présentée par Nagui. En octobre 2015, l'émission est de retour à l'antenne en prime time sur France 2.

${ }^{7}$ Chabada est une émission musicale présentée par Daniela Lumbroso, diffusée sur France 3 entre 2009 et 2013.

8 Beuve-Méry, A. (2013, 20 juin). France Télévisions relance sa plateforme numérique consacrée à la culture. Le Monde.fr. Repéré à : http://www.lemonde.fr/actualite-medias/article/2013/06/20/france-televisions-lanceune-plateforme-numerique-consacree-a-la-culture $34330923236 . \mathrm{html}$
} 


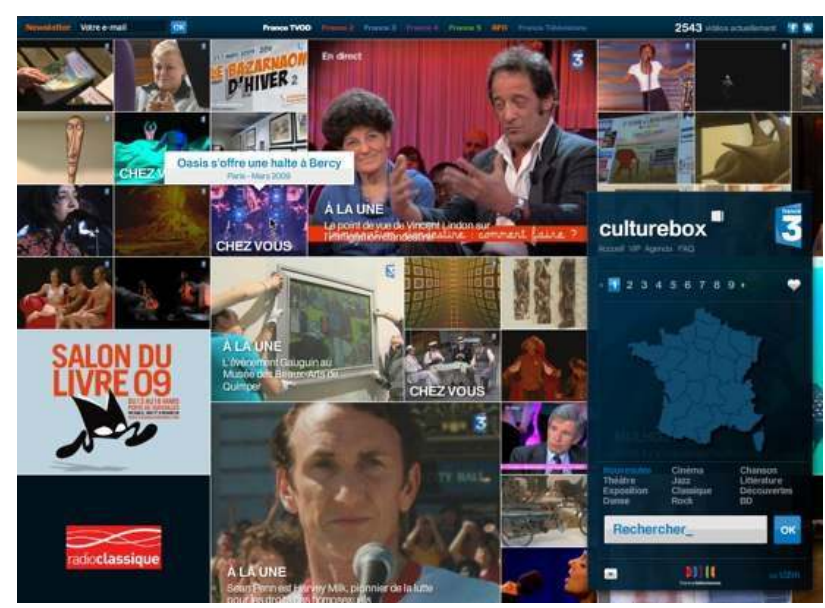

Figure 1. Mosaïque de vidéos sur l'écran d'accueil de Culturebox en $2009^{9}$

Nous allons voir que la refonte du dispositif Culturebox se lit alors comme une réponse aux objectifs liés au numérique fixés dans le Contrat d'Objectifs et de Moyens 2011-2015 et reformulés dans celui de 2016-2020. Pour ce premier axe de l'étude, nous nous appuierons sur une approche inspirée par la modélisation telle que proposée par la «théorie francophone des industries culturelles " (voir Miège, 2012) afin de penser la dynamique de diffusion de la culture sur Culturebox.

\subsection{Un portail développé par la « marque éditeur » France Télévisions Éditions Numériques}

Le directeur de la stratégie nous explique que le dispositif n'est pas directement lié à une chaîne du groupe public et les contenus ne sont pas conçus pour le "second écran ». La consultation de Culturebox renvoie donc aux pratiques liées aux « écrans connectés ». Depuis 2011, la filiale du groupe public FTVEN, anciennement France Télévisions Interactive, développe la stratégie numérique des chaînes et notamment Culturebox. France Télévisions Éditions Numériques a été renommée de cette manière afin d'insister sur sa fonction d'éditeur face à ce flux de contenus à destination du public. Notre interlocuteur explique :

\footnotetext{
${ }^{9}$ Source de l'image : https://fredcavazza.net/2009/03/05/france3-et-sa-mosaique-devideos-sur-culturebox/.
} 
Culturebox, le portail culturel au cœur de la stratégie numérique de France Télévisions

"La marque éditeur, c'est quand le public se trouve face à une offre pléthorique, il a besoin de repères, de prescripteurs. Je pense que le fait que ce soit la marque France Télévisions ou son service culturel Culturebox qui lui recommande des contenus peut être un élément de choix » (Directeur de la stratégie, 27 juin 2014).

Les contenus sélectionnés et alimentés par les collaborateurs du portail de service public constitueraient un premier écrémage pertinent et attractif pour l'usager. Selon notre interlocuteur, FTVEN agirait ainsi comme une balise, un repère permettant de sélectionner des contenus au sein d'une offre importante.

Selon la différenciation entre "plateforme " et " portail » proposée par Vincent Bullich et Thomas Guignard (2013), Culturebox présente les caractéristiques du portail numérique :

Le modèle du portail s'apparente sur de nombreux points à celui de la plateforme. La différence notable se joue sur la fonction prescription. Alors que la prospection de contenus, l'édition et/ou la production de contenus apparaissent comme des dimensions constitutives du portail, ces activités sont externalisées dans le modèle de la plateforme qui est par définition ouverte. Le gestionnaire de plateforme s'ouvre à tout éditeur de contenus respectant un cahier des charges plus ou moins contraignant selon les acteurs. L'intégration des contenus à une plateforme se fait donc sur la base d'un cahier des charges et d'une charte commune à tous les utilisateurs et non dans le cadre d'un processus de sélection qui caractérise le "modèle " du portail. Une plateforme n'intègre pas de fonction d'édition et présente donc un faible processus d'éditorialisation, à l'inverse du modèle du portail qui implique lui, également une transaction en amont pour l'obtention des contenus (ou alors une production en interne). (s. p.)

Dès 2013, lorsque France Télévisions dévoile le nouveau visage du dispositif Cuturebox alors refondu, le groupe le qualifie de " plateforme culturelle ${ }^{10}$ ", ce qui renvoie à l'acception commune du terme désignant un dispositif numérique sur Internet ; cela est un effet de la circulation de cette " inscription »

\footnotetext{
${ }^{10}$ Voir : https://culturebox.francetvinfo.fr/aide.
} 
(Labelle, 2001) discursive. L'avatar numérique de France Télévisions produit, édite ses propres contenus et les éditorialise dans une perspective multimédiatique (télévision et web). Le contenu produit est financé par l'entreprise dont le souhait est de développer une stratégie éditoriale et, donc, de garder un contrôle sur ces mêmes contenus. Outre le fait qu'elle réclame qu'une attention particulière soit portée aux activités de l'équipe journalistique, le portail nous invite à penser la façon dont les contenus sont diffusés. À l'inverse, une plateforme comme YouTube n'engage pas de processus d'édition de contenus (ceux-ci étant produits à l'extérieur du dispositif et de façon autonome) et engage seulement un processus d'éditorialisation ${ }^{11}$ a minima, se contentant d' " héberger » des vidéos et ne cherchant pas à définir une ligne éditoriale ou à opérer des choix de mise en visibilité autres que ceux proposés par l'algorithme de popularité, la recommandation personnalisée et la sélection de contenus « poussés » dans le cadre de partenariats commerciaux.

Dans le cas du portail, l'éditorialisation répond à une logique de l'offre qui se manifeste par la mise en œuvre d'une ligne éditoriale définie en amont. Dans le cas de la plateforme, l'éditorialisation est davantage conduite par la demande (recommandations algorithmiques en fonction des choix des internautes et des choix personnels). Sur Culturebox, les choix opérés par la rédaction supplantent les exigences de réponses à une demande supposée.

Ainsi, au "modèle de flot " (Miège, 2017) qui caractérise la diffusion télévisuelle de la culture par France Télévisions, s'adjoint une organisation suivant le modèle du portail dans leur offre culturelle numérique. Dès lors, pourquoi ce modèle a-t-il été retenu, au détriment de celui de la plateforme, pour incarner cette «culture de service public » au-delà de l'antenne linéaire?

\footnotetext{
${ }^{11}$ Ainsi que le définissent Michaël E. Sinatra et Marcello Vitali-Rosati (2014), « le mot "éditorialisation" met l'accent sur les dispositifs technologiques qui déterminent le contexte d'un contenu et son accessibilité [...]. L'éditorialisation regroupe toutes les actions destinées à structurer, rendre accessible et visible un contenu sur le web. » (p. 9)
} 
Culturebox, le portail culturel au cœur de la stratégie numérique de France Télévisions

\subsection{Une boîte à culture aux visages pluriels}

Conscient des enjeux de diffusion et d'atteinte des audiences liés au développement des techniques de communication numérique, le groupe tente de répondre à la multiplication des pratiques audiovisuelles. Avec une fréquentation mensuelle moyenne de 1,7 million de visites entre septembre 2014 et novembre 2014, France Télévisions évoquait un « record d'audience " avec une progression de fréquentation de $+210 \%$ depuis son lancement en juin $2013^{12}$.

Cette "verticale culturelle » est pensée en addition de la grille de programmes linéaires et permet dès lors de dépasser les contraintes liées aussi bien au format médiatique, au fond et au nombre de contenus diffusés (Levoin et Louessard, 2018). II s'agit d'une offre tout à la fois plurielle (en matière de formats), diverse (en matière de contenus culturels) et plurimédiatique. En 2014, celle-ci rassemble donc des articles relatifs à l'actualité culturelle (dans un onglet "Actu ») rédigés par les rédacteurs de Culturebox ou sous forme de communiqués reprenant des dépêches de l'Agence France Presse - ce qu'une plateforme ne permet pas -, la rediffusion d'émissions culturelles des chaînes du groupe (comme La Grande Librairie, Ce soir (ou jamais!), ou D'Art d'Art, dans un onglet "Émissions »), la diffusion de spectacles en direct sur le site web ou en replay (disponibles pendant plusieurs mois dans un onglet "Live ", 6 mois en moyenne), et les spectacles diffusés en exclusivité numérique ou spécifiquement captés pour une diffusion sur le portail.

En 2017, l'offre d'émissions s'est restreinte à l'émission délinéarisée Des mots de minuit, qui est toujours intégrée à Culturebox et Culturebox le mag qui propose « toute l'actualité culturelle du moment vue par Leila Kaddour et les journalistes de France Télévisions. Reportages, interviews, chroniques, 30 minutes pour tout savoir, le samedi $(11 \mathrm{H} 40)$ et dimanche $(16 \mathrm{H} 40)$ sur franceinfo ${ }^{13}$ ». Dès 2013, avec cette nouvelle offre, France Télévisions prend ainsi une position claire et affirmée

12 Nouveaux records d'audiences pour Culturebox, Le blog de FTVEN. Repéré à : http://blog.francetv.fr/ftven/2014/11/19/nouveaux-records-daudience-pourculturebox.html.

${ }^{13}$ Voir : http://culturebox.francetvinfo.fr/culture/culturebox-le-mag. 
dans le domaine culturel ${ }^{14}$ : proposer une offre large et variée de spectacles et de contenus rédactionnels.

\subsection{Une volonté d'adapter l'offre aux pratiques de visionnage}

Bien qu'adapté à la lecture sur tous types de terminaux, au départ, Culturebox a été conçu « comme une expérience de grand écran, de salon ", explique notre interlocuteur : "C'est le produit le plus télévisuel de nos produits numériques, même s'il est complètement délinéarisé, car c'est un produit pour regarder les contenus " (Directeur de la stratégie, 27 juin 2014). Les " contenus " sont redéfinis dans cette intervention : l'objectif étant de produire des «contenus » qui pourront être visionnés non plus dans un programme, mais dans un catalogue. Dans cette perspective, le portail apparaît à sa refonte comme un dispositif configuré de façon optimale pour la télévision connectée et la consommation de vidéos de concerts ou de spectacles vivants.

Dès 2013, l'accent a donc été mis sur l'écran de la télévision connectée, l'expérience est orientée dans cette perspective, la taille de l'écran apparaissant comme une condition nécessaire à la pleine appréciation des contenus. Le groupe public met par conséquent en avant une conception fidèle à «l'esprit du téléviseur " même s'il se déplace vers les contenus numériques. Sur la télévision connectée, les concepteurs ont travaillé à une simplification de l'expérience et de l'interface qui propose un menu à quatre flèches permettant de ne visionner que les Live de spectacles et des playlists, et permettant à l'usager de construire et de choisir son programme par une « lecture gestualisée » (Jeanneret, 2014) ${ }^{15}$.

Sur les trois autres supports (web depuis un ordinateur, web mobile et tablette), un principe d'accumulation de vignettes donne l'impression que les propositions de visionnage sont

\footnotetext{
14 Précisons qu'Arte a également mis en place un portail culturel dédié aux festivals, à la musique, à la danse, aux marionnettes, au cirque et à l'opéra. II s'agit d'ARTEConcert, anciennement ARTELiveWeb créé en 2009, dont le nom a changé en 2014 afin d'harmoniser l'ensemble des portails de la chaîne. Voir, à ce sujet : Auburtin, 2016.

${ }^{15}$ En juillet 2016, FTV cesse d'offrir ses services sur les téléviseurs connectés. Voir : Arrêt des services de télévision connectée. Le blog de FTVEN. Repéré à : http://blog.francetv.fr/ftven/2016/07/12/arret-des-services-de-televisionconnectee.html
} 
Culturebox, le portail culturel au cœur de la stratégie numérique de France Télévisions

infinies - et rappelle la mosaïque de la première version de Culturebox (voir la Figure 1).

Ainsi, le portail modifie les conditions d'accès à la culture en fonction des supports de réception. II met en scène le choix par l'usager, choix relatif sur la programmation de la télévision linéaire. Contrairement au "modèle de flot" (Miège, 2017) caractérisant la diffusion télévisuelle traditionnelle fonctionnant sur un principe de programmation linéaire, le portail numérique présente des caractéristiques favorisant une forme d'individualisation des pratiques (Miège, 2017), en raison d'une réception sur des terminaux individuels. Cependant, on constate que, malgré cette orientation vers une individualisation croissante qui constitue un aspect inédit dans l'offre culturelle de France Télévisions, le portail présente, dans sa dernière version, des traits architextuels et éditoriaux tout à fait classiques, ce qui tend à le rapprocher de formes médiatiques traditionnelles.

\section{Les logiques d'hybridation à l'œuvre dans la configuration des pratiques d'écritures des contenus}

Désormais, nous allons tâcher de montrer que la configuration des pratiques d'écritures des contenus à l'œuvre dans le dispositif Culturebox relève d'une logique d'hybridation empruntant à différents formats éditoriaux et logiques architextuelles bien identifiés. Nous empruntons le concept d'architexte à Yves Jeanneret et Emmanuël Souchier (1999). II est un " outil présent dans les écrits d'écran qui se situe à l'origine des actes d'écriture et de lecture des usagers et en régit le format » (Jeanneret, 2014, p. 10). Si l'hétérogénéité des sources de contenus rappelle le modèle de la plateforme, nous allons voir que Culturebox développe des contenus audiovisuels et rédactionnels en s'appuyant sur le format du magazine culturel en ligne pour défendre une certaine idée de la culture. 


\subsection{Les logiques architextuelles de l'écran d'accueil : un emprunt au format des magazines culturels en ligne}

La forme des textes sur l'écran d'accueil et les modalités de consommation des contenus sur Culturebox sont régies par un "architexte " spécifique. Cette perspective d'analyse nous permet de voir que la dimension télévisuelle n'est plus du tout ni revendiquée ni rappelée à l'internaute.

Cette approche par l'étude de l'« architexte » nous permet ici de montrer que la structure de l'écran d'accueil de Culturebox est très proche de celle de Télérama. $\mathrm{fr}^{16}$. Nous proposons dès lors de mettre en évidence quelques-unes des logiques architextuelles qui traversent les formes lisibles de l'« écrit d'écran " (Jeanneret et Souchier, 1999) faisant office d'accueil du portail. Autrement dit, en mettant en évidence ces logiques, nous interrogeons des implications formelles et éditoriales. Nous proposons de mettre en regard la structure des écrans d'accueil du 15 mars 2017 de Culturebox et de Télérama.fr (dont le portail a été créé en 1997), consultés depuis un ordinateur personnel (Figure 2).
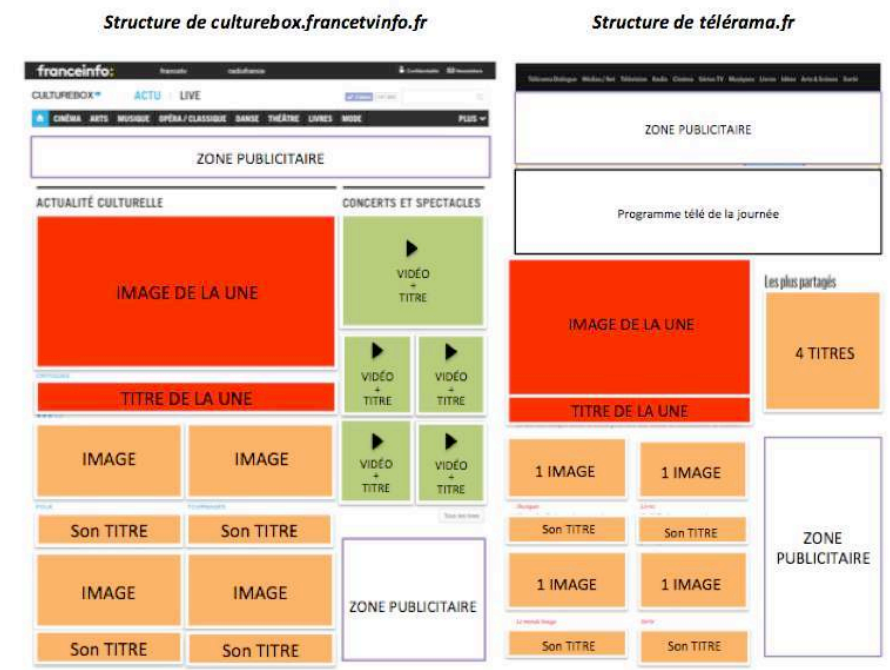

Figure 2. Mise en évidence de la structure des écrans d'accueil du 15 mars 2017 des portails de Culturebox (à gauche) et de Télérama.fr (à droite)

${ }^{16}$ Voir : http://www.telerama.fr/. 
Culturebox, le portail culturel au cœur de la stratégie numérique de France Télévisions

Cette schématisation montre les éléments communs des deux structures dans des couleurs identiques:

- l'univers éditorial est mis en évidence : les vidéos sont en vert, les illustrations des articles prennent la forme de vignettes et leur titre, ou simplement le titre des articles sans illustration, sont en orange ;

- la bannière du rubriquage est en haut de l'écran d'accueil ;

- les unes sont en rouge vif ;

- les zones publicitaires sont encerclées en violet.

Les similitudes formelles des deux pages apparaissent de manière évidente. Cette analyse des "écrits d'écran " peut rejoindre ce que Sébastien Rouquette (2009) nomme, dans une autre perspective théorique que celle empruntée par Jeanneret et Souchier (1999), un " caractère stéréotypé des visuels » et une « convergence des formats".

Considérant qu'un architexte oriente l'écriture des rédacteurs et la lecture des usagers d'un site, qu'il impose des formes à la présentation de l'écrit et de l'image, il s'agit alors d'apprécier comment celui de Culturebox configure les représentations de la culture telle qu'elle est promue par le groupe public.

Sur l'écran d'accueil, les logiques architextuelles imposent des figements; ce rapport à des "écrits sous contrainte " (Jeanne-Perrier, 2005) s'atténue en appréciant la diversité des " signes passeurs » (Jeanneret, Le Marec et Souchier, 2003) du portail (titres cliquables, items classés, lecteurs vidéo, boutons de " partage " vers les réseaux sociaux numériques, etc.). La mise en évidence des ces logiques architextuelles à l'œuvre sur l'écran d'accueil de Culturebox montre que la dimension télévisuelle cède sa place au format du magazine culturel en ligne.

\subsection{Les temporalités de la culture en réseaux}

Le territoire du numérique permet une «latitude du point de vue temporel», en offrant d'abord «au téléspectateur un ajustement à ses contraintes personnelles, une réappropriation de la temporalité télévisuelle plutôt qu'une émancipation totale » (Kredens et Rio, 2015, p. 25). 
La mise en évidence des logiques de l'architexte de l'écran d'accueil de Culturebox, ainsi que l'observation du portail, va désormais nous permettre de relever différentes formes d'accessibilité à la culture et une structuration autour de marqueurs temporels : le contenu principal se situe toujours au centre, à quoi s'ajoute un système de marges autour d'une signalétique particulière, indiquant le degré d'actualité des événements couverts, comme un lien "Dans l'actu » ou les bannières "Live" et " $A$ r revoir ", ou encore la bannière "Archives» avec les descripteurs des années au bas de l'écran d'accueil.

Alors que la représentation scénique et la grille télévisuelle dépendent d'une programmation, Culturebox réenvisage ces temporalités liées à l'agenda culturel et médiatique. Les formes d'accessibilité à la culture sur Culturebox évoluent autour de : contenus disponibles en live, qui rappellent le rendez-vous télévisuel; de contenus informatifs, liés à une actualité culturelle, et d'autres relevant de la critique; et des contenus sous forme de culture archivée ${ }^{17}$.

2.2.1. Les " Live " en live streaming ou en replay : une réinterprétation du rendez-vous télévisuel

Depuis l'onglet "Live », les spectacles vivants sont soit des retransmissions de contenus exclusifs diffusées en live streaming, c'est-à-dire sur le mode du direct, ou des captations visibles en replay, c'est-à-dire sur le mode de la télévision de rattrapage, soit des spectacles qui sont ou sont sur le point d'être parallèlement diffusés sur une chaîne. Avec les "Live ", FTVEN met en commun les ressources culturelles négociées pour une diffusion sur Culturebox. La question du financement par les usagers du portail de France Télévisions se limite à la redevance. Le directeur de la stratégie (27 juin 2014) explique que cela facilite les relations avec les ayants droit :

« Notre objectif est justement l'exposition. Ce n'est pas faire des recettes, de toute façon ce ne sont pour l'essentiel pas des programmes pour lesquels la question des recettes se pose. Cela nous donne la liberté de

17 Précisons que les remarques ci-après s'appuient sur des observations du portail principalement réalisées en 2014. 
Culturebox, le portail culturel au cœur de la stratégie numérique de France Télévisions

discuter avec les gens, de les convaincre de nous donner les droits, et cela permet aux œuvres d'exister. "

II est intéressant de constater que notre interlocuteur considère proposer des contenus qui sont, par ailleurs, pas ou peu valorisables.

Depuis la réforme de l'audiovisuel de 2009, conduite par Nicolas Sarkozy, la pression publicitaire est moins importante pour la télévision publique. II subsiste néanmoins une tension entre volonté de démocratisation et démocratie culturelles ${ }^{18}$ et logique d'audimat. Or la flexibilité des nouveaux écrans est l'occasion d'exposer une large palette d'œuvres qui ne sont pas diffusées ou pas diffusables pour des raisons techniques à l'antenne. Par exemple, l'opéra Einstein on the Beach (2014) aurait été particulièrement difficile à programmer sur les antennes linéaires à cause de sa durée de 3 h 43 min.

Par ailleurs, Culturebox permet au téléspectateur de s'affranchir des grilles de programmes imposées par le « modèle de flot » caractérisant traditionnellement la télévision. II peut composer son propre menu culturel. L'idée de rendezvous télévisuel n'en est pas moins réinterprétée. En effet, une rhétorique du direct est effective, notamment à l'approche de la diffusion d'un spectacle capté en direct et diffusé en streaming live. Comme l'illustre la Figure 3 , une bannière annonce, en haut de l'écran d'accueil, le direct à venir.

\footnotetext{
18 Les termes démocratisation culturelle et démocratie culturelle se réfèrent aux politiques culturelles. La démocratisation culturelle consiste en un travail de renforcement de l'accès des publics aux œuvres et aux disciplines consacrées institutionnellement. La démocratie culturelle, quant à elle, repose sur un principe d'inclusion de toutes les formes de pratiques culturelles. Sur ce sujet, voir entre autres : Martin, 2013.
} 


\section{Lucie ALEXIS}

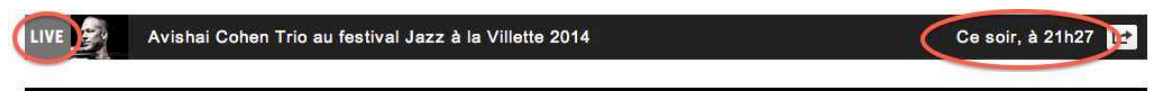

LIVE LA UNE

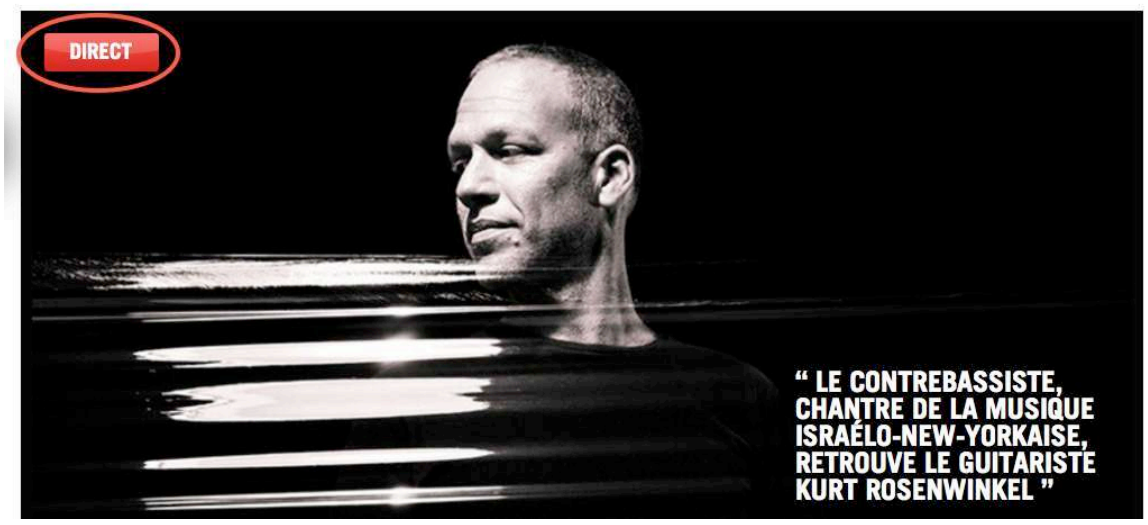

Figure 3. Capture d'écran mettant en visibilité l'approche d'un spectacle en direct sur l'écran d'accueil de Culturebox

(5 septembre 2014)

Culturebox fait office de médiateur ${ }^{19}$ entre l'usager et les lieux de culture qui se dédoublent alors sur le numérique. Le direct à venir est indiqué par un rectangle rouge, signalétique qui met en valeur l'événement à ne pas manquer. Enfin, un phénomène d'annonce, par un décompte, indique sur un Live à venir la date et l'heure de sa mise en ligne (Figure 4).

19 Nous entendons ici le terme médiateur dans une acception proche de celle énoncée par Jean Caune (2017), c'est-à-dire comme un acteur visant tout à la fois à favoriser l'accès aux œuvres d'art, construire des communautés et des individus, et renforcer l'exercice démocratique. 
Culturebox, le portail culturel au cœur de la stratégie numérique de France Télévisions

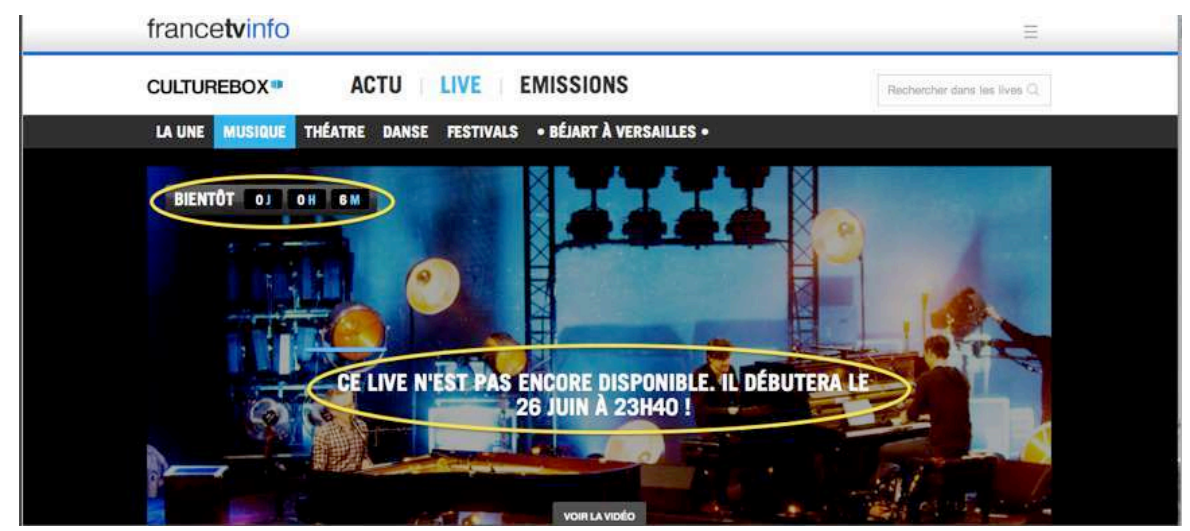

Figure 4. Capture d'écran de Culturebox montrant un décompte avant la diffusion d'un Live (26 juin 2014)

Avec un décompte créant un effet d'attente, l'éditeur replace la grandeur du rendez-vous télévisuel. L'ensemble de ces éléments converge vers une rhétorique de rendez-vous dont on multiplie les annonces et qui est alors réinventé sur le portail.

\subsubsection{Les « Actu » : l’agenda culturel défini par le portail}

Un autre avantage du portail, par rapport à la plateforme, est la présence de sujets traités dans la rubrique "Actu », relevant à la fois de l'information brute et de genres journalistiques plus travaillés, impliquant davantage les journalistes rattachés, par exemple, à la critique culturelle, aux reportages ou aux interviews. Différents niveaux d'accès à ces informations sont observables: le temps de l'information quasi instantanée, avec des articles relevant d'une pratique de desk web, publiés «Par Culturebox (avec AFP) », qui ne nécessite pas une implication particulière de la part du journaliste, si ce n'est la mise en forme ; et un temps court, avec des articles, des interviews, des critiques, écrits par les rédacteurs et qui peuvent être illustrés par des reportages audiovisuels diffusés sur les chaînes du groupe. On notera que sur le plan des choix éditoriaux, la une n'est pas mise en avant par des mesures d'audience et n'est pas non plus imposée algorithmiquement par une métrique fondée sur la popularité. En cela, le fonctionnement de Culturebox se rapproche de celui qui prévaut dans les rédactions de la presse magazine hebdomadaire. Ainsi, l'information est régulièrement alimentée sur Culturebox; le 
portail décide de ce qui fait l' " événement » et quelles sont les «tendances ».

\subsection{Culture archivée et numérique : une chance pour la valorisation des œuvres ?}

En bas de l'écran d'accueil se trouvent les «signes passeurs " vers les archives des articles disponibles sur Culturebox. Cette forme d'accès aux contenus rédactionnels attachés à l'archive est liée à une dimension documentaire et intègre l'idée de patrimonialisation de l'actualité et de la critique du spectacle vivant. Culturebox aurait une politique visant à constituer un patrimoine culturel à l'instar d'un musée et de ses collections permanentes. Les Live, en revanche, ne sont laissés que quelques mois en ligne avant d'être supprimés. Ce sont les chaînes Culturebox sur YouTube et Dailymotion qui, en plus d'être des adjuvants promotionnels du portail, prennent la fonction d'archivage des vidéos de spectacles vivants. Quant aux émissions culturelles du groupe, il est possible de les revoir à son propre rythme, au-delà des sept jours de rattrapage proposés par le portail de diffusion en continu gratuite francetv pluzz (existant jusqu'à la création du portail France.tv ${ }^{20}$ en mai 2017).

Ainsi, pour éditorialiser son offre, le portail Culturebox emprunte des modèles médiatiques déjà institués autour d'une logique d'agrégation de contenus. II se positionne, à l'instar d'un magazine culturel en ligne, en faisant coexister plusieurs dimensions temporelles et formes d'accès à la culture autour : 1) de vidéos en direct ; 2) de contenus rédactionnels renvoyant à une actualité culturelle; et 3 ) de vidéos en replay et d'articles archivés.

${ }^{20}$ Voir : https://www.france.tv/. 
Culturebox, le portail culturel au cœur de la stratégie numérique de France Télévisions

\section{Une politique éditoriale de service public véhiculée par le portail}

La proposition d'un environnement médiatique où s'agrègent différents formats éditoriaux, permis par le modèle du portail, serait une réponse de FTV pour proposer une politique éditoriale de service public en cohérence avec celle de l'antenne linéaire (de France 2). Ce type d'éditorialisation des contenus, caractéristique du portail - se distinguant de celui des plateformes, orienté par la demande (recommandation algorithmique notamment) -, rend dès lors plus applicable un contrôle éditorial difficilement tenable sur une plateforme : si le choix de l'entreprise avait été d'intégrer exclusivement une chaîne YouTube ou Dailymotion, par exemple, le risque aurait été de noyer cette ligne éditoriale du fait d'une hétérogénéité des sources présentées sur ces dispositifs d'hébergement. L'enjeu est ici relatif à l'énonciation éditoriale (Souchier, 1998) : FTV a ainsi préféré une maîtrise affirmée du dispositif d'énonciation (bien qu'il y ait tout de même certaines vidéos qui renvoient sur YouTube).

Le directeur de la stratégie (27 juin 2014) précise que «le vrai rôle de l'éditeur est d'épurer, de préciser pour une meilleure compréhension. Si l'on parle de mission de service public, si vous n'aidez pas un petit peu les gens à hiérarchiser le contenu, ils sont pris dans le flux ". Le plus grand groupe audiovisuel public parie sur l'idée d'une marque de service public aisément identifiable et historiquement « rassurante » pour le public.

Poursuivant notre démarche sémiologique autour de l'architexte de l'écran d'accueil, nous allons nous intéresser maintenant aux contenus des sujets présentés et verrons que le portail est un modèle plus adapté à l'élaboration et au contrôle d'une ligne éditoriale que la plateforme, car il permet de conserver une totale maîtrise sur les conditions d'exposition et de diffusion des éléments rédactionnels.

\subsection{Un large périmètre de la culture proposée dans le rubriquage : la non-hiérarchisation des genres culturels comme ligne éditoriale}

"Souvent, l'image de Culturebox est plutôt festival "Baroque-Bach-Clavecin", mais c'est aussi beaucoup de 


\section{Lucie ALEXIS}

musique contemporaine, c'est toutes les cultures, sans hésiter. Toutes les formes culturelles ॥, garantit le directeur de la stratégie (27 juin 2014). II met en avant, ici, l'absence de hiérarchisation des disciplines artistiques et des formes d'expressions culturelles et assume un relativisme culturel qui serait à l'œuvre sur Culturebox.

Culturebox reprend des éléments formels et éditoriaux que l'on trouve dans la presse culturelle en ligne dont le parangon est Télérama.fr. Le rubriquage par genre culturel fait écho à ce que l'on trouve sur ce portail de «référence ». Ceci n'est absolument pas neutre, puisque ces emprunts s'appuient sur des conceptions de la culture et du rôle du prescripteur culturel que l'on peut envisager comme partagés par les deux portails.

En effet, l'offre proposée par FTV balaie une diversité de genres et de disciplines artistiques. Entre 2013 et 2017, le rubriquage s'affine progressivement ${ }^{21}$. En 2017, les grandes rubriques sont: "Cinéma », «Arts », "Musique », "Opéra/Classique », "Danse », "Théâtre ", "Livres », " Mode », " Patrimoine », « Blogs » et " Des mots de minuit ». $\mathrm{Si}$ la télévision est coutumière du fait de penser une catégorisation des émissions par genres télévisuels dans un but de lisibilité et de classement des contenus, les magazines culturels en ligne le font par le rubriquage par disciplines artistiques ou par catégories culturelles, à l'instar de Télérama.fr. La Figure 6 met en regard les bannières horizontales des écrans d'accueil de Culturebox et de Télérama.fr consultées depuis un ordinateur personnel.

21 Par exemple, les rubriques et sous-rubriques de 2014 étaient celles-ci : " Cinéma » (sorties, stars, critiques, tournages, etc.) ; "Expositions » (peinture, patrimoine, sculpture, photo) ; "Musique » (pop, rock, rap, électro, classique, opéra, jazz/blues, live, etc.) ; "Scènes » (théâtre, danse, événements, humour, cirque, etc.) ; "Tendances » (mode, design, architecture, street art, style et défilés, télé, etc.) ; « Livres » (rentrée littéraire, romans, essais-documents, beaux-livres, etc.). 
Culturebox, le portail culturel au cœur de la stratégie numérique de France Télévisions

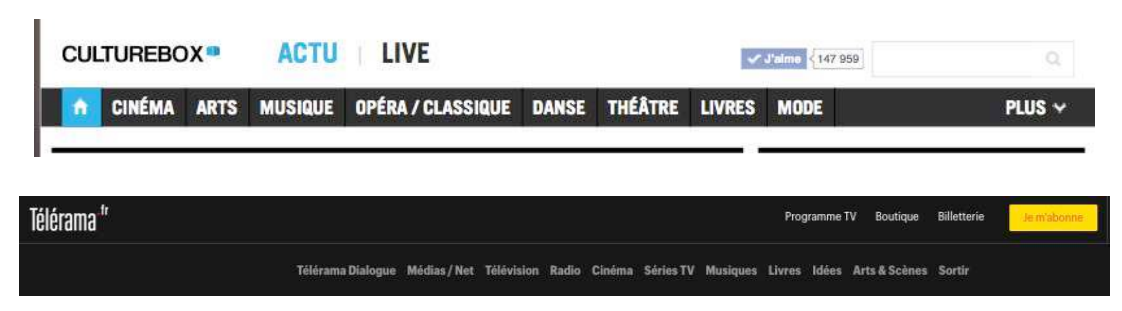

Figure 5. Capture d'écran des bannières (consultées depuis un ordinateur personnel) montrant les rubriquages sur les écrans d'accueil de Culturebox (mars 2017, en haut) et de Télérama.fr (septembre 2017, en bas)

Ainsi, l'ordonnancement proposé reprend d'une part une thématisation dans la tradition académique, c'est-à-dire liée aux grandes disciplines artistiques, celles qui constituent précisément l'organisation des directions générales du ministère de la Culture et de la Communication ; d'autre part, il reprend des genres issus de productions des industries culturelles (par exemple, la " Mode» ou "Série/TV »). Si ce n'est l'ordre d'apparition sur la bannière, les différents domaines culturels connaissent le même traitement dans le rubriquage. Aucun genre n'est, dans la présentation visuelle, mis plus en avant qu'un autre. Les contenus sont également répartis sous un autre type de catégorisation: "Actu " et "Live ». En outre, chacune de ces rubriques se décline en sous-genres culturels (Figure 6) : 


\title{
Lucie ALEXIS
}

\author{
Cinéma : Tout le cinéma, Sorties, Stars, Critiques, \\ Tournages, Comédie, Drame, Policier/Thriller, \\ Action/Aventure, Fantastique, Documentaire, \\ Animation/Jeunesse, Dossiers, DVD, Court- \\ métrage, Événements. \\ -Arts : Tous les Arts, Peinture, Sculpture, Photo, \\ Expos, Street Art, Architecture, Design, Numérique, \\ Événements. \\ -Musique: Toute la musique, Pop, Rock, Rap, \\ Électro, Jazz/Blues, Soul/Funk, Folk, Musique du \\ monde, Chanson française, Variété internationale, \\ Métal, Hard rock, Reggae, RoB, Événements. \\ - Opéra/Classique : Tout l'Opéra/Classique, \\ Opéra, Musique classique. \\ - Danse: Toute la Danse, Danses urbaines. \\ Danses du monde, Danse contemporaine. \\ - Théâtre: Tout le Théâtre, Comédie, Théâtre \\ classique, Théåtre contemporain, Théâtre de rue. \\ - Livres: Tous les Livres, Romans, \\ Essais/Documents, Beaux livres, Bande-dessinée, \\ Jeunesse, Biographie/Mémoire, Poésie/Théâtre, \\ Pratique, Policier, Événements. \\ - Mode : Toute la mode, Style et défilés, Créateurs, \\ Métiers d'art, Événements. \\ L'onglet «Plus» de la page d'accuell consultée \\ depuis un ordinateur personnel permet d'ouvrir un \\ menu déroulant et de découvrir de nouvelles \\ rubriques : \\ - Scènes \\ Patrimoine : Tout le Patrimoine, Histoire. \\ - Séries/TV \\ A ces rubriques, s'y ajoutent deux autres : \\ - Blogs : Le bento, Voyageurs de notes, London \\ Box, BD-Box \\ - Des mots de minuit.
}

Figure 6. Les sous-genres culturels présentés sur l'écran d'accueil de Culturebox

Nous constatons une volonté de traiter un maximum de territoires culturels. Culturebox semble d'emblée proposer une représentation large de la culture. Tout d'abord, un maximum de sous-catégories sont proposées par les menus déroulants du portail. Celles-ci se réfèrent en outre très distinctement à la terminologie issue de la "pop culture », soit l'ensemble des éléments proprement signifiants ou symboliques produits ou diffusés par les médias, ainsi que le définissent notamment les Cultural Studies (Storey, 2018). On croise ainsi des catégories comme « RnB », « Street Art », « Thriller », etc. 
Culturebox, le portail culturel au cœur de la stratégie numérique de France Télévisions

En outre, la rubrique "Blogs " correspond à des blogues partenaires de Culturebox dont les auteurs ont des statuts différents: par exemple, les blogues d'étudiants (Le Bento), d'un amateur éclairé (Voyageur de notes), d'un correspondant de FTV (London blog). Si notre interlocuteur déclare "Pour nous, Culturebox est une manière de faire une chaîne culturelle à la demande » (Directeur de la stratégie, 27 juin 2014), cette rubrique "Blog " est très mimétique par rapport à la presse en ligne. Les sites de presse ou de magazines, tels que Le Monde.fr ou Télérama.fr, laissent en effet une place aux blogues. Quant à la rubrique Des mots de minuit, elle héberge la chaîne numérique du programme, à laquelle un lien renvoie directement. Cette multiplicité de "signes passeurs" vers d'autres sites, cette organisation réseautique contribue à la caractérisation de Culturebox comme un portail et non comme un " simple » site de contenus édités.

L'équipe éditoriale a donc l'ambition de couvrir un maximum de formes d'expression et d'événements. Aussi, nous pouvons envisager ce rubriquage selon deux angles : le premier permet de voir que le site est conçu en partie en fonction d'une conception préalable de la culture qui pose, de façon très académique, comme grandes rubriques les principales disciplines artistiques, répondant alors à une logique de démocratisation culturelle; le second, l'étude des sousrubriques, permet de faire ressortir une conception de la culture plus foncièrement liée aux produits et aux pratiques des industries culturelles. En outre, l'offre du portail permet d'identifier une autre ligne de partage entre, d'une part, des contenus manifestement très grand public, traitant de sujets susceptibles d'attirer une large audience, et, d'autre part, des contenus relatifs à des univers culturels qui renvoient davantage à des formes peu médiatisées, plus confidentielles, c'est-à-dire se réalisant en marge des principaux circuits institutionnels et commerciaux de diffusion de la culture. Par conséquent, Culturebox, parce qu'il propose une offre complémentaire des chaînes de France Télévisions, ouvre l'offre culturelle du groupe audiovisuel à des registres parfois plus pointus et, de fait, remplit une mission de service public en élargissant la palette des couleurs culturelles traitées par l'entreprise publique. 
L'observation de cette éditorialisation témoigne d'une volonté d' " horizontalité » entre les contenus proposés, c'est-à-dire le refus d'une axiologie fondée sur la distinction «haute culture/culture populaire » (Levine, 2010). Ce refus de hiérarchisation converge vers la mission de service public, déployée au sein du projet numérique global, d' " offrir le plus grand nombre de contenus de qualité au public le plus large 22 ». Notons cependant une tentative de hiérarchisation par les collaborateurs du portail basée sur le nombre de vues (onglet « Les plus vus »), qui emprunte à la logique de mise en visibilité telle qu'on l'observe sur les principales plateformes de vidéos. On peut désormais s'interroger sur la représentativité de ces différentes formes culturelles dans l'offre globale du portail.

\subsection{Une « culture de service public » cohérente sur l'antenne linéaire de France 2 et Culturebox}

Nous proposons ici d'identifier les spécificités de la ligne éditoriale de Culturebox en ciblant les titres des unes de l'écran d'accueil du portail. Particulièrement visibles, ils manifestent efficacement la conception de la culture que FTV souhaite transmettre. Nous avons construit un corpus de unes en en sélectionnant une quotidiennement durant le mois de mars 2017 (31 unes). Nous souhaitons nous questionner sur la prétention à la légitimité de ce portail : met-il en avant certains sous-genres culturels plutôt que d'autres dans les unes? Certains contenus sont-ils davantage mis en avant?

À partir des 31 titres répertoriés, nous avons construit une grille d'analyse afin d'identifier quels étaient les genres les plus représentés. Les premiers codages recensent, notamment, les informations identifiant a minima les contenus suivants :

- le rubriquage principal sur le portail et le rubriquage spécifique du contenu ;

- le genre artistique ou culturel mis en avant au sein de l'article. ${ }^{23}$

\footnotetext{
22 Voir : https://www.francetelevisions.fr/missions.

23 Nous avons ensuite procédé aux codages suivants sur chacun des articles: le registre et le genre journalistiques, la citation du nom d'un artiste ou d'une personnalité issus du monde de la culture ou d'une œuvre ou d'un lieu culturel.
} 
Culturebox, le portail culturel au cœur de la stratégie numérique de France Télévisions

II apparaît que les genres les plus représentés sont principalement ceux relatifs aux grandes disciplines artistiques : musique, cinéma, arts plastiques, livre, audiovisuel, bande dessinée, danse. Le théâtre, la mode et le patrimoine sont sous-représentés ${ }^{24}$.

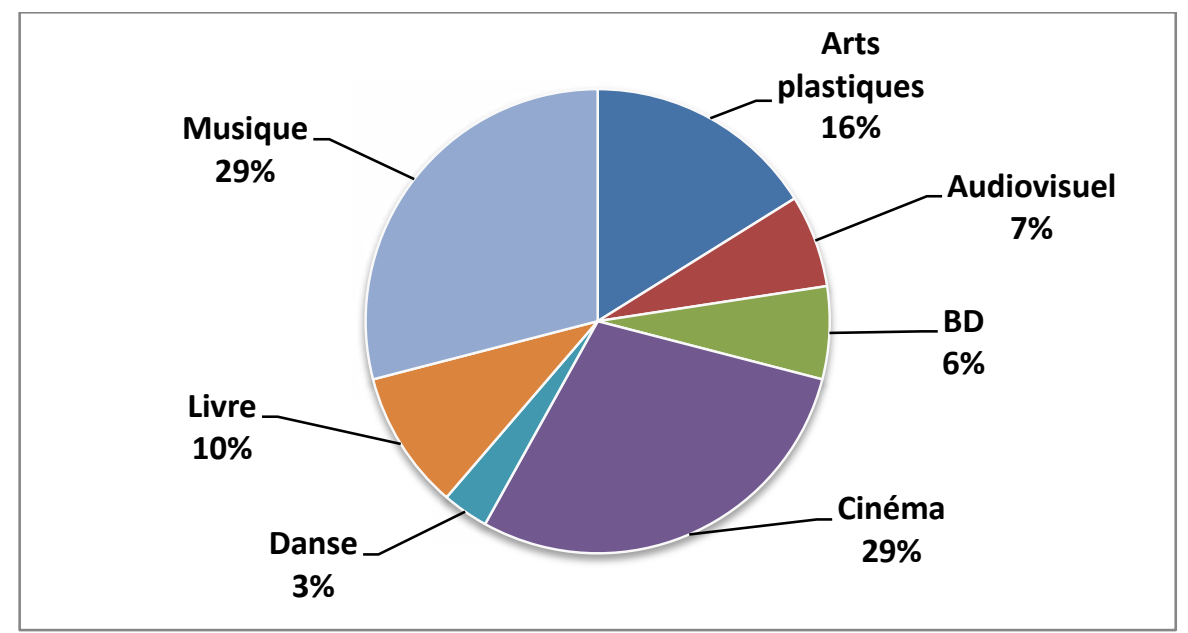

Figure 7. Graphique en secteurs représentant les genres artistiques en une de Culturebox, mars 2017

II semble clair que la musique et le cinéma sont les deux genres artistiques les plus représentés (à $29 \%$ chacun), puis les arts plastiques (16\%), l'audiovisuel, le livre et la bande dessinée se situent entre 6 et $10 \%$, la danse n'est représentée qu'à $3 \%$.

Ces chiffres montrent la prévalence dans les sujets des unes des formes culturelles les plus faciles d'accès : le cinéma et la musique (principalement des musiques actuelles sous leur forme enregistrée). On remarque donc d'emblée une surreprésentation des produits des industries culturelles par rapport au spectacle vivant et aux arts plastiques.

Dans cette recherche de compréhension de l'offre culturelle de Culturebox, nous avons enfin mené une étude sur les qualités "socioéconomiques », c'est-à-dire attribuées collectivement aux objets mis en une par le portail sur la période considérée. Pour ce faire, deux métriques d'évaluation

${ }^{24}$ L'explication de cette situation mériterait une étude ultérieure. 


\section{Lucie ALEXIS}

ont été privilégiées: la plus ou moins grande reconnaissance institutionnelle des objets considérés et le plus ou moins grand investissement financier dans la production de l'objet (investissement rapporté au genre de celui-ci), comme symptôme de l'échelle de diffusion escomptée. Nous appuyant sur la terminologie mise en place par Philippe Bouquillon $(2010)^{25}$, nous distinguons ainsi des produits "premiums ", ayant nécessité d'importants investissements et étant destinés à une large audience, et des produits de niche, moins coûteux à produire, mais bénéficiant généralement d'une diffusion plus confidentielle. C'est l'une des ambitions des concepteurs du dispositif: "On pense vraiment que les médias de service public doivent apporter ce bénéfice d'expérience. On conçoit les produits numériques moins comme des produits de mass media que comme des produits de médias de précision qui vont être capables de s'adresser à une multitude de niches ", affirme notre interlocuteur (Directeur de la stratégie, 27 juin 2014).

Nous avons réalisé des métriques autour de la
« reconnaissance institutionnelle » et du «niveau d'investissement (relatif) " des objets. Pour cela, nous avons pensé un diagramme (Figure 8) constitué d'un axe horizontal évaluant le plus ou moins grand investissement financier dans la production de l'objet, en distinguant ce qui relève plus ou moins de la "culture "premium" " ou de la "culture de niche » définies ci-dessus. L'axe vertical évalue la plus ou moins grande reconnaissance institutionnelle d'un objet ou d'un artiste. II s'agissait d'identifier ceux qui avaient reçu des prix ou des distinctions en intégrant ce que nous avons appelé "culture reconnue par l'institution » sur la représentation visuelle. Cette reconnaissance de différentes « institutions culturelles », qui récompensent, chaque année pour la plupart, le travail de créateurs contemporains, donne d'emblée une visibilité médiatique aux objets. À l'inverse, par «culture marginale », nous renvoyons aux formes peu médiatisées et plus confidentielles de la culture.

25 Sur cette « bipolarisation » de la production culturelle, Bouquillon (2010) explique : « La bipolarisation signifie que les productions de contenus s'orientent dans deux voies, soit la production de contenus premium, aux coûts élevés et assumés par les grands acteurs des filières, soit la production, par les acteurs des franges des oligopoles, de contenus à bas coûts » (paragr. 52). 
Culturebox, le portail culturel au cœur de la stratégie numérique de France Télévisions

La Figure 8 présente donc le diagramme à partir de deux axes consignant nos métriques et sur lequel nous avons placé les objets culturels, identifiés dans les 31 unes, en fonction du codage défini dans la grille d'analyse.

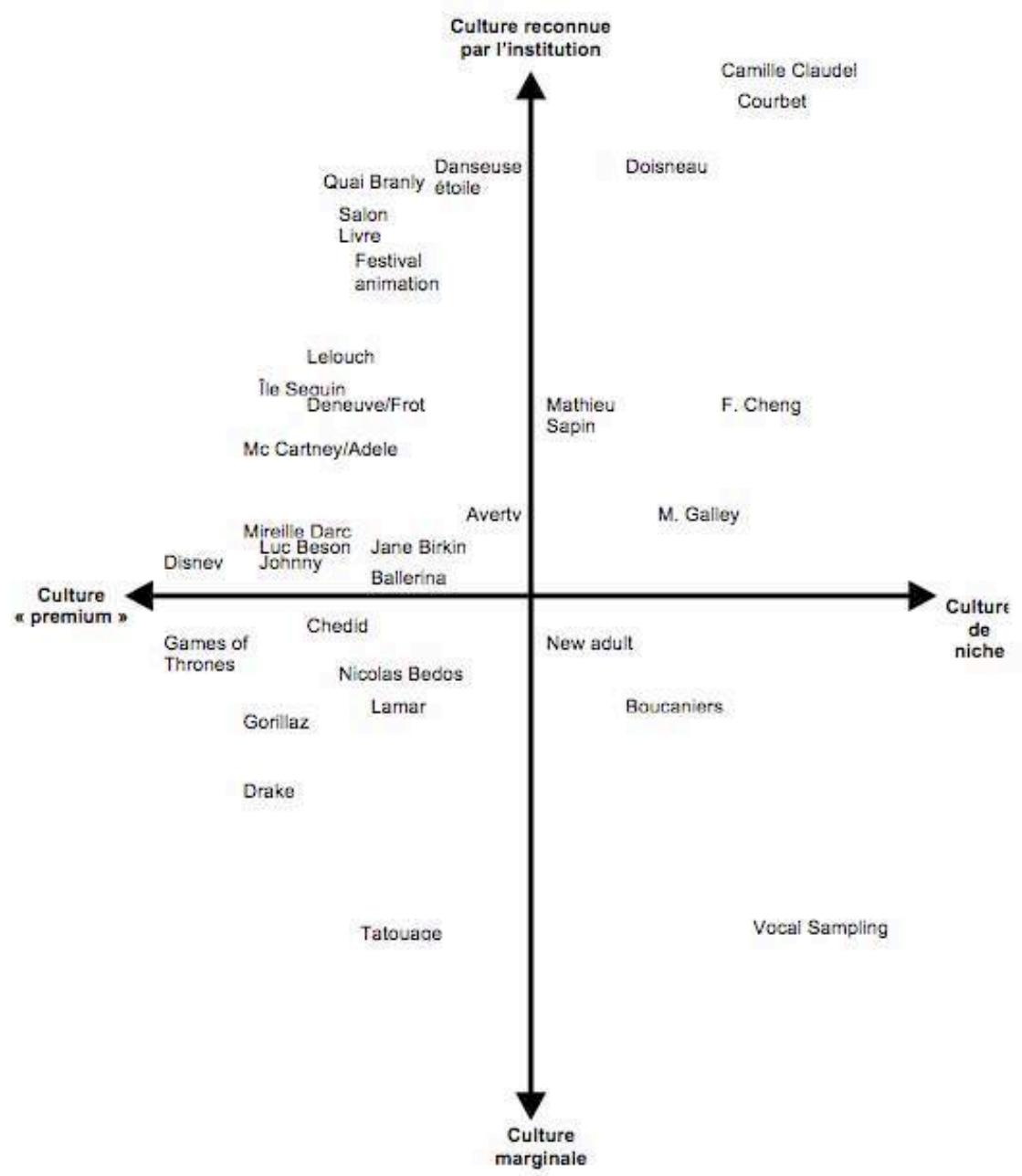

Figure 8. Les positionnements socioéconomiques des objets culturels présentés en une de Culturebox en mars 2017

Il apparaît que les produits premiums, à la fois fédérateurs et nécessitant de larges investissements, sont largement majoritaires. Les objets reconnus institutionnellement sont également plus traités que les autres. La culture promue par les unes de Culturebox de notre corpus est donc une culture 
principalement produite par les industries culturelles, par distinction avec le spectacle vivant et les arts plastiques. Toutefois, elle reste encore largement marquée par les mécanismes de consécration institutionnelle. Celle-ci peut se comprendre comme la conjugaison d'exigences portées par les annonceurs et d'exigences relatives aux missions de service public auxquelles doit répondre le portail. Dans le premier cas, il s'agit d'agréger des audiences multiples et versatiles afin de pouvoir vendre des espaces médiatiques aux annonceurs. Dans cette perspective, les objets considérés comme a priori fédérateurs ou au potentiel élevé de diffusion sont privilégiés (la variable d'investissements productifs apparaissant comme décisive pour identifier de tels objets). Dans le second cas, il s'agit de promouvoir des objets institutionnellement reconnus, mais dont certains peuvent souffrir d'un moindre intérêt du " grand public ». Par ailleurs, nos observations nous amènent à penser que la culture dite "alternative », peut-être plus " pointue » et spécialisée, "la contre-culture » ou les cultures « underground ${ }^{26}$, comme le propose, par exemple, le magazine Tracks d'Arte, sont peu représentées sur Culturebox.

Notre recherche doctorale (Alexis, 2017) nous a conduite à conclure que, sur les plateaux d'émissions de France 2 entre 2010 et 2011, le type de culture observé a une double origine, au croisement de la culture institutionnellement reconnue et de celle produite ou diffusée par les médias traditionnels. Une culture plus marginale est moins présente. Ainsi, le portail reproduit sur Internet le positionnement culturel identifiable sur l'antenne linéaire du groupe, tout en ouvrant davantage le traitement de produits confidentiels. C'est ainsi une " culture de service public » cohérente que l'on trouve sur les services de France Télévisions.

\section{3. Éléments de réflexion concernant le public}

Le directeur de la stratégie explique que les collaborateurs de FTVEN visent principalement deux publics à qui adresser le nouveau visage de Culturebox: un public néophyte, curieux, qui ne se rend pas dans les lieux dédiés à la culture, et le "public jeune », en mettant l'accent sur les possibilités d'enrichissements télévisuels et les outils de partage (Directeur

${ }^{26}$ À ce sujet, voir notamment : Greil, 2000. 
Culturebox, le portail culturel au cœur de la stratégie numérique de France Télévisions

de la stratégie, 27 juin 2014). Ces dispositifs d'inscription sont en effet a minima présents sur le portail. Notons des changements significatifs liés aux possibilités de partage: en 2014, il n'y avait pas de "signes passeurs " vers les chaînes Dailymotion et YouTube de Culturebox; en 2017, alors que les plateformes ont particulièrement leur place dans l'univers médiatique, le portail y renvoie.

Dans la lignée d'une volonté ministérielle telle qu'elle est visible dans, notamment, l'action de Jack Lang et visant à l'articulation des objectifs de démocratisation et de démocratie culturelles, Culturebox agit en faveur d'une mise en visibilité de tous les genres artistiques et pratiques culturelles. Mais notre observation nous suggère que la tonalité dominante du périmètre de la culture à l'œuvre sur le portail s'adresse plutôt à des personnes "cultivées a priori ». Depuis la fin des années 1990, la figure dominante du consommateur culturel est celle de l' "omnivore culturel » proposée par Richard A. Peterson (2004). Si le portail a pour ambition de s'adresser à tous les publics, les choix de traitement des contenus nous amènent à penser que seront touchées principalement des personnes déjà cultivées et qui sont susceptibles de s'intéresser à une diversité de genres et sous-genres culturels et artistiques.

En cela, Culturebox fait moins preuve de pédagogie qu'il ne répond à une mission de prescription telle que l'a initiée la critique littéraire dès le $17^{\mathrm{e}}$ siècle. Néanmoins, en s'adressant à "tous les cultivés", Culturebox conserve, malgré tout, une vision de service public, permise par le principe d'éditorialisation sur le portail - dont un rubriquage - proche du magazine en ligne. Sur une plateforme, nous faisons l'hypothèse que les modalités de navigation relèvent davantage de la flânerie de lien en lien.

\section{Conclusion}

Ainsi, nous avons souhaité montrer que les formes d'organisation médiatique peuvent être appréciées au regard de leurs stratégies éditoriales. S'agissant de la programmation culturelle en ligne, FTV a préféré le modèle du portail afin d'insister sur sa "marque éditeur " et conserver un contrôle éditorial. Le groupe a donc opté pour l'inscription de formats 
éditoriaux déjà connus dans une chaîne numérique. Au sein de ce portail cohabitent une culture médiatique et populaire et une culture institutionnellement consacrée, une culture grand public et fédératrice et une culture plus confidentielle et spécialisée. Mais deux cultures prédominent : une culture marquée par les mécanismes de consécration institutionnelle et une culture dite "premium ». Cette cohabitation se lit dans la mixité des sujets traités, mais également sur les différents supports médiatiques et modes de diffusion qu'implique le portail (vidéo en replay, vidéo en direct, article). Cette ligne éditoriale est proche de celle déployée sur l'antenne linéaire de France 2 et produit dès lors une "culture de service public" cohérente sur les antennes linéaire et délinéaire. FTV se positionne ainsi comme un énonciateur sur différents supports (format télévisé, magazine culturel en ligne) et, dans le même temps, il revendique une fonction médiatrice entre les phénomènes culturels et les citoyens qui s'inscrit dans la mission de service public.

Le recours aux modèles socioéconomiques des industries culturelles nous a permis de mettre en évidence le fait que s'agrègent différents modèles de diffusion de la culture et des natures de contenus différents sur le portail. Celui-ci hybride ainsi une logique de programmation linéaire issue d'un " modèle de flot » (avec l'idée de rendez-vous télévisuel et de contenus audiovisuels programmés sur le site) : un emprunt au modèle de la presse avec une périodicité affirmée dans la publication des articles, avec le nombre important d'articles publiés et avec une domination de l'écrit; et une inspiration des modes de fonctionnement de la presse en ligne avec la présence des blogues. À cela s'ajoute une logique d'accès temporaire au contenu telle qu'on la trouve sur les plateformes de vidéos à la demande. Dans le dispositif, l'usager peut donc jongler avec les différentes modalités de consommation des contenus auxquelles la télévision, la presse et le Web l'ont déjà habitué.

Dans Le Levain des médias. Forme, format, média, Guillaume Soulez et Kira Kitsopanidou (2015) expliquent que la " convergence numérique " et l'émergence des écrans connectés ont bouleversé les pratiques de consommations médiatiques. Dans ce cadre, la télévision, tout comme le cinéma, traverse une "zone de turbulences intermédiales » 
Culturebox, le portail culturel au cœur de la stratégie numérique de France Télévisions

(p. 241) et une métamorphose de ses formats. Ils amènent l'idée d'un "levain des médias ", " c'est-à-dire [l'idée] d'une force interne qui agit, au sein d'un média donné, sur la dimension morphologique de ce média, le médium » (p. 241). Le média, en tant qu'organisation sociale, reconfigurerait le médium, c'est-à-dire le matériau formel. II s'agit donc « de penser la part du média dans les formes, voire le média comme source formelle » (p. 241).

Autrement dit, ce concept de "levain des médias " est particulièrement pertinent pour montrer comment un média agit en son propre sein sur ses formes propres ou bien sur des formes empruntées à un autre média. Nous avons montré que le dispositif Culturebox, conçu pour donner accès à la vidéo, s'est progressivement positionné comme un magazine culturel en ligne. Le portail s'appuierait finalement sur des formats déjà employés : le groupe audiovisuel public, en déployant son offre sur Internet, s'adapte aux formats éditoriaux répandus sur celuici.

Les différentes analyses des formes sur l'écran ont montré que la forme de Culturebox participerait de cette transformation morphologique du média télévision. Par exemple, la multiplicité des "signes passeurs " conduit à repenser le zapping télévisuel sur Internet. Philippe Marion (1997) évoque ainsi une pratique de "surfing" (p. 70). Juxtaposé aux articles, un système de "signes passeurs » («Thématiques liées », «À lire aussi ») oriente la lecture des usagers sur le portail et conduit à proposer une idée de réseau culturel attenant - et justifie également le qualificatif de «portail ». La présence du rubriquage, quant à elle, concourt à produire un média télévisuel en ligne s'appuyant sur le modèle avantageux du portail pour permettre à la télévision publique un contrôle éditorial.

Enfin, alors que, sur les antennes linéaires, les temps de publicité entrecoupent les émissions, plusieurs espaces sont dévolus aux annonceurs - l'analyse architextuelle de l'écran d'accueil de Culturebox l'a montré. Des messages publicitaires sous forme de vidéos en "pré-roll " apparaissent également avant le visionnage des spectacles ou des concerts. Être face à de la publicité devient habituel au sein de nos pratiques de lectures sur le Web. Cela participe d'une banalisation de cette hybridation de contenus sur l'écran : publicité et objets culturels 


\section{Lucie ALEXIS}

s'appréhendent au sein d'un même espace visuel. La publicité aurait finalement une dimension "infra-ordinaire ${ }^{27}$ " (Souchier, 2007) sur le Web. Or ce n'est pas sans constater que ces usages, devenant implicites et inconscients jusqu'à disparaître à nos yeux, s'inscrivent dans la lignée de ceux de la presse.

Que ce soit par l'approche par les modèles socioéconomiques, par la théorie des écrits d'écran ou à travers cette conception d'un «levain des médias ${ }^{28}$ ", nous voyons que les formats éditoriaux procèdent par altération, tout en s'inscrivant dans des généalogies médiatiques.

\section{Références}

Alexis, L. (2017). Réponses à la mission culturelle de la télévision publique. Analyse sémiologique des rapports institutionnels, des figures de l'artiste et des écritures numériques à France Télévisions (1993-2017) (Thèse de doctorat). Université Paris 2 Panthéon-Assas, Paris.

Auburtin, M. (2016). La diffusion d'opéras de l'écran de télévision aux nouveaux écrans. Dans J. Châteauvert et G. Delavaud (dir.), D'un écran à l'autre. Les mutations du spectateur (p. 343-357). Paris, France : L'Harmattan.

Bouquillion, P. (2010). Industries, économie créatives et technologies d'information et de communication. tic\&société, 4(2). doi: 10.4000/ticetsociete.876

Bullich, V. et Guignard, T. (2013, mai). L'intégration des contenus aux plates-formes numériques: une analyse par filière. Communication présentée au Colloque international Industries de la culture et de la communication, industries créatives : un grand tournant ?, École nationale supérieure Louis Lumière La Cité du Cinéma, La Plaine Saint-Denis, France.

\footnotetext{
${ }^{27}$ Le concept d' « infra-ordinaire », dans l'approche de Souchier, s'inspire de celui de Georges Perec et se rapporte aux « petites choses, à des détails infimes qui nous fondent et qui, à force de petitesse, disparaissent à nos yeux inattentifs " (Souchier, 2012, paragr. 3). Ceux-ci contribuent néanmoins de façon cruciale aux processus communicationnels.

${ }^{28}$ Nous tenons à préciser, toutefois, que ces trois perspectives sont très éloignées les unes des autres, voire divergentes. Cependant, elles nous permettent toutes de penser la généalogie médiatique.
} 
Culturebox, le portail culturel au cœur de la stratégie numérique de France Télévisions

Caune, J. (2017). La Médiation culturelle. Expérience esthétique et construction du Vivre-ensemble. Grenoble, France : Presses universitaires de Grenoble.

Donnat, O. (2010). Les pratiques culturelles à l'ère numérique. Bulletin des bibliothèques de France, (5). Repéré à http://bbf.enssib.fr/consulter/bbf-2010-05-0006-001

Greil, M. (2000). Lipstick Traces. Une histoire secrète du vingtième siècle. Paris, France : Folio.

Jeanneret, Y. (2014). Critique de la trivialité. Les médiations de la communication, enjeu de pouvoir. Paris, France: Non standard.

Jeanneret, Y. et Souchier, E. (1999). Pour une poétique de l'écrit d'écran. Xoana, (6), 97-107.

Jeanneret, Y., Le Marec, J. et Souchier, E. (dir.) (2003). Lire, écrire, récrire. Paris, France : BPI.

Jeanne-Perrier, V. (2005). L'écrit sous contrainte: les Systèmes de management de contenu (CMS). Communication et langages, (146), 71-81.

Kredens, E. et Rio, F. (2015). La télévision à l'ère numérique : entre pratiques émergentes et reconfiguration de l'objet médiatique. Études de communication, (44), 15-28.

Labelle, S. (2001). " La société de l'information », à décrypter !. Communication et langages, (128), 65-79.

Levine, L. W. (2010). Culture d'en haut, culture d'en bas. L'émergence des hiérarchies culturelles aux États-Unis. Paris, France : La Découverte.

Levoin, X. et Louessard, B. (2018). YouTube et les chaînes de télévision: des modèles socio-économiques en question. Actes vol. 2. Modèles et stratégies d'acteurs du Congrès de la SFSIC de juin 2018, 157-168.

Marion, P. (1997). Narratologie médiatique et médiagénie des récits. Recherches en communication, (7), 61-88.

Martin, L. (2013). La démocratisation de la culture en France. Une ambition obsolète?. Territoires contemporains, (5). Repéré à http://tristan.u-bourgogne.fr/CGC/publications/ Democratiser culture/Laurent Martin.html 
Miège, B. (1996). La société conquise par la communication. Grenoble, France : Presses universitaires de Grenoble.

Miège, B. (2012). La théorie des industries culturelles (et informationnelles), composante des SIC. Revue française des sciences de l'information et de la communication, (1). Repéré à http://journals.openedition.org/rfsic/80

Miège, B. (2017). Les industries culturelles et créatives face à l'ordre de l'information et de la communication. Fontaine, France : Presses universitaires de Grenoble.

Mœglin, P. (2005). Outils et médias éducatifs. Une approche communicationnelle. Grenoble, France: Presses universitaires de Grenoble.

Peterson, R. A. (2004). Le passage à des goûts omnivores : notions, faits et perspectives. Sociologies et Sociétés, (1), 145-164.

Rouquette, S. (2009). L'analyse des sites Internet: une radiographie du cyberespace. Paris, France : INA Éditions.

Sinatra, M. et Vitali-Rosati, M. (2014). Pratiques de l'édition numérique. Montréal, Canada: Presses de l'Université de Montréal.

Souchier, E. (1998). L'image du texte pour une théorie de l'énonciation éditoriale. Les cahiers de médiologie, (6), 137145.

Souchier, E. (2007). Formes et pouvoirs de l'énonciation éditoriale. Communication \& langages, (154), 23-38.

Souchier, E. (2012). La mémoire de l'oubli: éloge de l'aliénation. Pour une poétique de "l'infra-ordinaire». Communication \& langages, (172), 3-19.

Soulez, G. et Kitsopanidou, K. (dir.) (2015). Le Levain des médias. Forme, format, média. Paris, France : L'Harmattan.

Storey, J. (2018). Cultural Theory and Popular Culture: An Introduction ( $8^{\mathrm{e}}$ éd.). Londres, Royaume-Uni/New York, NY : Routledge. 